\title{
Methylphenidate Induced Lip and Tongue Biting
}

\author{
Cem Gokcen ${ }^{1}$, Mehmet Karadag ${ }^{1}$, Ihsan Aksoy ${ }^{2}$ \\ ${ }^{1}$ Department of Child and Adolescent Psychiatry, Faculty of Medicine, Gaziantep University, Gaziantep, ${ }^{2}$ Department of Psychiatry, Adıyaman \\ University Research and Education Hospital, Adıyaman, Turkey
}

\begin{abstract}
Attention deficit hyperactivity disorder (ADHD) is a life-long neurodevelopmental disorder and treatment depends on pharmacotherapy because of its biological origin. Stimulant drugs are the most commonly used treatment for ADHD and they have various side effects. Herein, we report a case who bit off the tip of her tongue with Osmotic Release Oral System methylphenidate (OROS MPH) $36 \mathrm{mg} /$ day, bit the tip of her lower lip with immediate release (IR) MPH $10 \mathrm{mg} /$ day and lateral part of her tongue with IR MPH $20 \mathrm{mg} /$ day. A diagnosis of epilepsy was unlikely because of the normal neurological examination and electroencephalography findings. This case was considered as an atypical side effect of MPH such as perseverative/compulsive behaviours and movement disorders. Clinicians should be aware of that stimulant medications may cause lip and tongue biting behavior and this may effect treatment compliance tremendously.
\end{abstract}

KEY WORDS: Attention deficit disorder with hyperactivity; Stereotypic movement disorder; Methylphenidate; Lip biting; Tongue biting.

\section{INTRODUCTION}

Attention deficit hyperactivity disorder (ADHD) is a life-long neurodevelopmental disorder. that affects 6-9\% of children. ${ }^{1)}$ It is characterized by hyperactivity, impulsiveness, and a developmentally inappropriate lack of attention. Children suffering from ADHD have significant risk of long term social and academic problems. ${ }^{2)}$ The basis of ADHD treatment depends on pharmacotherapy. Stimulant drugs are the most commonly used treatment for ADHD which are suggested as first line therapy in all treatment guidelines. Beside the most frequently observed side effects of stimulant drugs like abdominal pain, nausea, loss of appetite, nervousness and insomnia, rare side effects like perseverative/compulsive behaviours and movement disorders are also reported. ${ }^{3)}$

There are several stimulant-induced movement abnor-

Received: November 17, 2016/Revised: February 3, 2017

Accepted: February 24, 2017

Address for correspondence: Mehmet Karadag, MD

Department of Child and Adolescent Psychiatry, Gaziantep

University, Faculty of Medicine, 27310 Sahinbey, Gaziantep, Turkey

Tel: +90-342-3606060-76464, Fax: +90-342-3603928

E-mail: mehmetkaradag1988@gmail.com

ORCID: https://orcid.org/0000-0002-4130-0494 malities including a variety of vocal and motor phenomena such as Tourette's syndrome and tics. Nevertheless these symptoms usually disappear when stimulant dose is lowered or the drug is discontinued. ${ }^{4)}$ On the other hand, in some cases several stimulant-induced obsessive-compulsive symptoms are described in literature. ${ }^{5,6)}$

In our case, we report a patient who had developed recurrent lip and tongue biting after the use of methylphenidate (MPH).

\section{CASE}

Twelve years old female patient presented to clinic with symptoms of attention deficit at home and school, including complaints of easily getting bored, forgetfulness in class as well as academic incompetence. She was diagnosed with predominantly inattentive subtype of ADHD, according to the Diagnostic and Statistical Manual of Mental Disorders, 5th edition (DSM-5), in our clinic. She had visited another child and adolescent psychiatry clinic 4 years ago with similar complaints, where she was diagnosed with ADHD and was prescribed Osmotic Release Oral System methylphenidate (OROS MPH) 18 mg/day. After this treatment the patient was reported to have bitten

(ㄷ) This is an Open-Access article distributed under the terms of the Creative Commons Attribution Non-Commercial License (http://creativecommons.org/licenses/by-nc/4.0) which permits unrestricted non-commercial use, distribution, and reproduction in any medium, provided the original work is properly cited. 


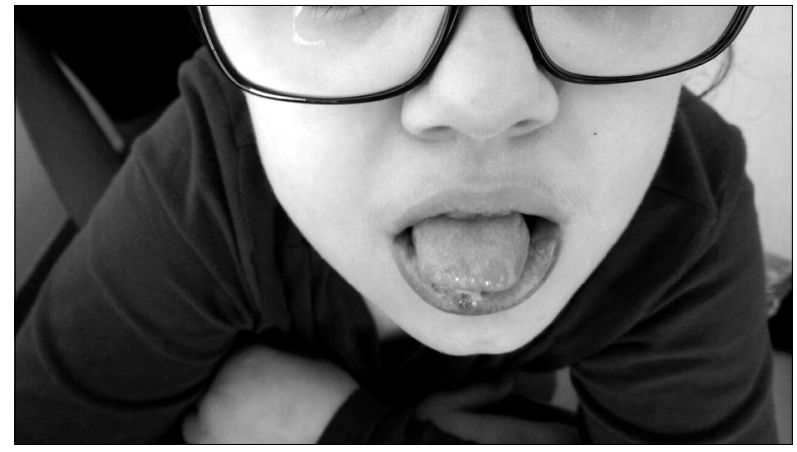

Fig. 1. The scar on the tip of tongue after the patient bit her tongue with Osmotic Release Oral System methylphenidate 36 mg/day.

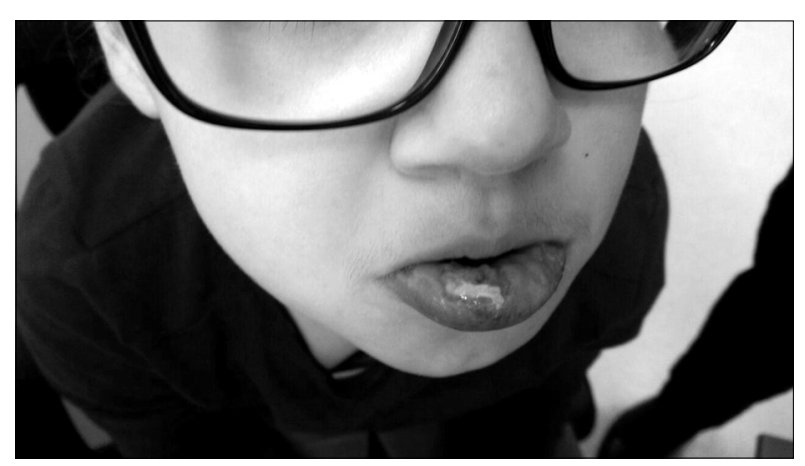

Fig. 2. The scar on the lower lip after the patient bit her lower lip with immediate release methylphenidate $10 \mathrm{mg} /$ day.

part of her tongue. Even though the complaints receded, due to their concerns about drug side effects, her family decided to discontinue the treatment. Atomoxetine was started instead. Seeing no benefit from atomoxetine, the patient received OROS MPH $27 \mathrm{mg} /$ day again, which was increased to $36 \mathrm{mg} /$ day in due course. The patient weighed $39 \mathrm{~kg}$ at this stage and $36 \mathrm{mg} /$ day was our target dose. During the period when the dose was being increased, the patient's family reported that the patient had an increased studying and attention time and she was getting bored less frequently. In spite of these improvements, two weeks after the increase in dosage, it was observed that the patient bit off her tounge. Due to this side effect and in response to the parents' demand, the drug was discontinued. To evaluate the symptom we requested a pediatric nerological consult and after neurological examination and electroencephalography (EEG) evaluation was done, the pediatric neurology department concluded that the symptom was not epileptic. As can be seen in Figure 1, the scar in the area where the patient bit her tongue could be observed on physical examination. After this incident of bit-

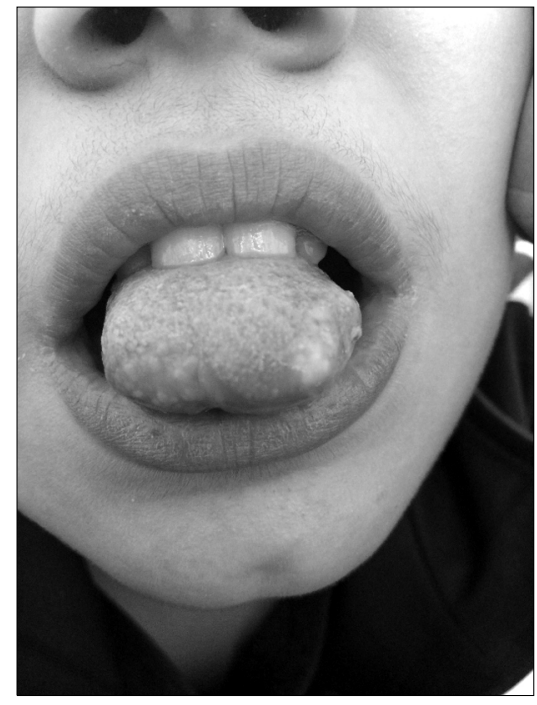

Fig. 3. The scar on the lateral tongue after the patient bit her tongue with immediate release methylphenidate $20 \mathrm{mg} /$ day.

ing, the patient's family refused further medical treatment. But after some time, as the patients ADHD symptoms continued, her parents applied to our clinic again to retry the treatment.

When she came to our clinic, the patient was started with $10 \mathrm{mg} /$ day short acting immediate release (IR) $\mathrm{MPH}$. Following this treatment, she suddenly and involuntarily bit the tip of her lower lip (Fig. 2). She was reviewed after a 5 week medication-free period; her ulcer was almost healed, although some visible scars were left. The tounge or lip biting syptom did not reoccur. After her ulcer healed, IR MPH $10 \mathrm{mg} /$ day was started again with no side effects but she bit off lateral side of her tongue the day dose was increased to $20 \mathrm{mg} /$ day (Fig. 3). A detailed psychiatric and neurological evaluation was made after the biting. Psychiatric evaluation did not reveal any psychotic symptoms, major psycosocial stressors or mood disturbances in the patient's life that could result in self-biting symptoms. She has no known drug or food allergies so far. The patient's grandmother was reported to have obsessive-compulsive disorder and there was no other family history of psychiatric disorders. Drug therapy was discontinued and she did not bite her tongue or lip again through two months of follow-up. For the continuing ADHD symptoms, the patient was directed to a government-funded special education program where she could receive extra one-to-one lessons. 


\section{DISCUSSION}

Tounge and lip biting behavior of the present case can be evaluated as an uncommon presentation of MPH side effect, resembling perseverative/compulsive behaviours and movement disorders (orofacial, stereotypic movements and tics) ${ }^{7)}$ which otherwise commonly results in side effects such as abdominal pain, nausea, loss of appetite, nervousness and insomnia. On the other hand, epilepsy can cause tongue and lip biting behavior, nevertheless normal neurological examination and EEG findings helped us rule out the diagnosis of drug-induced epilepsy. In the literature, there are a limited number of publications related to the stereotyped movements associated with the use of MPH. In a study with rats and rabbits, self-chewing/bitting/licking rates have shown to be increased with dose escalation. ${ }^{8)}$

In a 2003 case report, MPH was reported to cause obsessive-compulsive behaviour in a patient with no prior history of psychiatric disorders. ${ }^{6}$ In another study, obsessive compulsive behaviour was observed in 34 patients out of the 45 who were using psycostimulant medication for ADHD.?

In a study that examined switching from MPH-IR to OROS-MPH among children with ADHD, children on $\mathrm{MPH}-\mathrm{IR}$ treatment were shown to exhibit significantly more tics than with OROS-MPH treatment. ${ }^{3)}$

According to our knowledge, stereotypic self biting is a rare but major side effect due to $\mathrm{MPH}$. Clinicians should be aware that stimulant medications may cause lip and tongue biting behavior and this may significantly effect treatment compliance.

\section{REFERENCES}

1. Kessler RC, Berglund P, Demler O, Jin R, Merikangas KR, Walters EE. Lifetime prevalence and age-of-onset distributions of DSM-IV disorders in the National Comorbidity Survey Replication. Arch Gen Psychiatry 2005;62:593-602.

2. Friedlander AH, Friedlander IK. Dental management considerations in children with attention-deficit hyperactivity disorder. ASDC J Dent Child 1992;59:196-201.

3. Kim BN, Kim YN, Cheong US, Kim JW, Hwang JW, Shin MS, et al. Switching from methy/phenidate-immediate release (MPH-IR) to methylphenidate-OROS (OROS-MPH): A multicenter, open-label study in Korea. Clin Psychopharmacol Neurosci 2011,9:29-35.

4. Lowe TL, Cohen DJ, Detlor J, Kremenitzer MW, Shaywitz BA. Stimulant medications precipitate Tourette's syndrome. JAMA 1982;247:1168-1169.

5. Koizumi HM. Obsessive-compulsive symptoms following stimulants. Biol Psychiatry 1985;20:1332-1333.

6. Serby M. Methy/phenidate-induced obsessive-compulsive symptoms in an elderly man. CNS Spectr 2003;8:612-613.

7. Borcherding BG, Keysor CS, Rapoport JL, Elia J, Amass J. Motor/vocal tics and compulsive behaviors on stimulant drugs: is there a common vulnerability? Psychiatry Res 1990; 33:83-94.

8. Beckman DA, Schneider M, Youreneff M, Tse FL. Developmental toxicity assessment of d,/-methy/phenidate and d-methy/phenidate in rats and rabbits. Birth Defects Res B Dev Reprod Toxicol 2008;83:489-501. 